Por acuerdo de la Facultad publicamos la tesis: "Moral" $Y$ "Vida" en Federico Nietzsche. Razones de espacio nos obligan a dividiria en tres partes. Damos a continuación la primera parte:

\title{
"Moral" y "Vida" en Federico Nietzsche
}

\author{
I N T R O D U C C I O N
}

\section{I.-EL HOMBRE}

"Soy la llama $y$ al alumbrar me consumo" (Gay Saber, Preludio, 61).

SUMARIO.-Nietzsche: ¿Un filósolo?-La conciencià y la inconsciencia en su filosofia.-Nietzsche: espiritu dionisiaco, abogado del diablo--Sabio.-Horror y discreción de las verdades niezscheanas. - La filosofia de Nietzsche, confo. sión personal.-La fiebre y 1 balbuceo.- Nietzsche pedagogo, literato, psicólogo.-Religiosidad del poeta Nietzsche.-Nietzsche, padre nuestro.-NietzscheDionysios.

¿Fué Nietzsche do lveràsoun filósofo? ¿Aéaso gomo lo escribió en alguna célebre carta dosus últimos días lúcidos a Jorge Brandes no tenía importancia serlo o no? Quiza el no tenerla fue condición para que pudiera crear esa personalísima filosofía con que hoy nos regalamos: no ir en busca del yo filósofo sino serlo un poco como el sol, ignorante de la propia luz. No decisión consciente de ser un filósofo, más una vida vuelta filosofía, un serlo con todo el ser: "De la cabeza a los pies" y con la conciencia, pero sobre todo desde lo inconsciente. Más también conciencia de la necesidad de ser un pensador desde la inconsciencia, ante todo desde ella, aparece con mucha claridad en este nuestro otro Federido El Grande quien sostuvo que había que reconocer el carácter ante todo inconsciente de lo hasta entonces considerado como la más alta expresión de la vida consciente, del pensamiento filosófico.

Aceptado este carácter del "pensamiento filosófico" (Ortega diría que la frase es redundancia) y recordando aquella magistral y $\tan$ olvidada de Goethe: "El pensamiento no sirve de nada para pensar" podremos decir que Nietzsche fué un pensador, vale decir un pensador filosófico, un fi- 
lósofo y un gran filósofo que apenas si necesitó de pensamientos para pensar.

Y ateniéndonos a la sencilla etimología de filosofía también diremos que sí, que fué un amante de la sabiduría, un amante con amor intenso, obsesivo, pasional, con amor que se hace centro vital desde el que se arquitectura una vida, desde el que se arquitecturó esta ejemplar vida de Nietzsche. Y cuando nos dice (Zarathustra, el canto del baile) que se inclina a la sabiduría solo porque le recuerda bastante a la vida - "tiene su ojos, su risa y hasta su anzuelo dorado"- después es más sincero: "¿Qué he de hacer si se parecen tanto las dos?". Hoy nosotros con esa triste seguridad en el juicio que a veces da la perspectiva, podemos decir ya quién fué la preferida, la quizá a pesar de él mismo, preferida. Amante platónico y poseedor. Para Zweig un Don Juan del conocimiento, que buscaba, como éste en las mujeres a la mujer, él en las verdades a la Verdad que quizá estaba en iodas, que a lo mejor no era ninguna de ellas. Y fué amante que ofrendó destino y razón y que recibió en cambio - negociante al revés - apenas esa inmortalidad o eterna mortalidad del Retorno.

Pero también un espíritu dionisíaco, una vitalidad que usó el conocimiento como un modo delexpresión, que superó pronto aquella época de "la vida, una experiencia de quien busca el conocimiento" para llegar a otra más de acuerdo con ese él mismo que tan infatigablemente buscó en sí. Aunque hubiera preferido no sảber de la coincidencia con Kempis.

Y un abogado del diabloinperbo sólo ssecundariamente. "El diablo" un "incidente" en sentido jurídico, con la importancia de una como causa colateral de la gran causa de la vida a cuya defensa se entregó con todo él.

Y sabio en sentido etimológico. La oveja se come la corona del sabio pero él lo era, "sabio" saboreador. Aunque escribió lo de "Las mujeres más bellas, los vinos más generosos y los pensamientos, más fuertes" vivió transfigurados, en su saborear los pensamientos, los placeres del amor y la embriaguez.

Como políticos de modales refinados de los que penden millones de vidas son sus verdades: llevan dentro de sí los problemas más angustiosos, los interrogantes más terribles, las soluciones más desesperadas y audaces y son sin embargo discretas, educadas, sonrientes. Sus gritos de dolor y sus eurekas aún más terribles guardan, a pesar de su intensidad, los cuartos de tono. 
Nietzsche es la filosofía como confesión personal, como afirmación personal, como soberbia. Personalidad genial que desborda lo puramente filosófico y matiza su filosofía de riquísimos valores artísticos y religiosos. Que la hace ser también arte y religión, así sea la religión contradictoria del sin Dios, la vivencia religiosa de los opuestos Dyonisios - El Crucificado. Berdiaeff dice que Nietzscho es la más alta posibilidad del hombre sin Dios. Pero Dyonisios es también un Dios. Y en todo caso, ¿qué, si Dios ha muerto?

La obra de Nietzsche es una obra febril; el presente sin posibilidades ya está como atropellado por las más recónditas del porvenir; por eso el balbuceo, el tono profético, el entusiasmo, así sea este entusiasmo paradojal del sin Dios. El hombre que quiere que viva el superhombre. La religiosa e impía alegría de una muerte definitiva de Dios.

Se siente la impertinencia - y además la falta de buen gusto- si se habla de Nietzsche sin balbucear. Y no importa que él nos lo hubiera aconsejado - la infidelidad a Nietzsche es la más difícil de las táreas para quienes lo han conocido en el sentido bíblico vuelto metáforapues la trae la impaciencia que acompaña a la que importa, la vivacidad eterna que no es la vida eterna, el "subsistir zoológico comunicado al trasmundo", vivacidad que él poseyó y poseemos también nosotros por su celestinaje mágico...

¿Un pedagogo? Sí, más bien un conductor que un conducido pero conducido también por los problemas de la cultura occidental. Y por su genio. Y por la maravilla eircular del universo.S Conductor en un

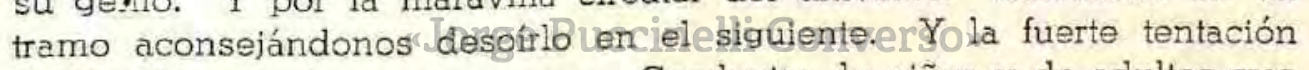
de desoírlo precisamente en eso. Conductor de niños y de adultos que felizmente recobran al niño. Y aún de jóvenes aunque diga: "Los jóvenes, son tan estúpidos".

Un literato. En ese su más allá de la modestia y de la inmodestia" del "Ecce Homo", Heine y él, los más grandes de la Alemania decimonónica. Animada, con espíritu, respirando, su letra: labios y voz suyos. Descubridor del "espíritu de la letra" y haciendo vivir la letra. Taumaturgo. Haciéndolas revivir si muertas: ¿Cuál de él muerta?

Archianalítico - lo anota Werfel-. Hizo no sólo psicología sino fisiología de las filosofías, de las que sin parecerlo eran también una filosofía. Su "Anticristo" es una fisiología del cristianismo. Y nuestra obligada aunque de algún mal gusto, reciprocidad: sus enfermedades, así su pensamiento sea reacción, lucha contra ellas, como consecuencia y figura de esa salud mejor que les debe. Su obra un poco como la definición del biólogo Bichat, de la vida: la no muerte. Un San Jorge venciendo 
recreó con ellos-. Y es en ellos que puede ser descuartizado. E: corte nos parece mejor que aquel otro - arbitrario y necesario- en épocas - etapas. Y así Zarathustra, Jesús, Dionysios, Sócrates, César Borgia, Wagner, Schopenhauer, Goethe, Napoleón aparecerían como resultado de este descuartizamiento. La opinión de él sobre ellos como un indicio de estos personajes en él, que vivió y que fué. Y después el milagro dionisíaco de Nielzsche-Dionysios. Los pedazos unidos. Nietzsche-Dionysios resucitado y uno. Deshecho el milagro durante su larga enfermedad pero presente en sus palabras. Palabras que cuando de Nietzsche no se deben escribir tres veces.

\section{II.-I.A OBRA}

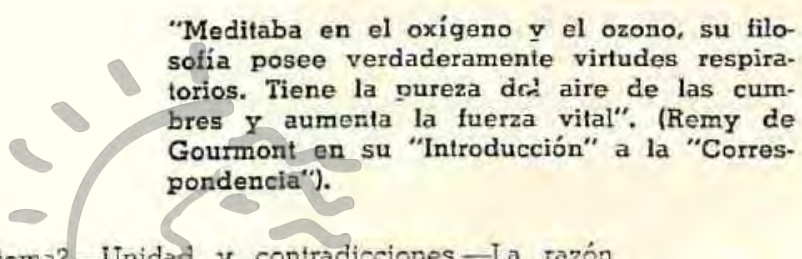

SUMARIO.- $i E s$ su obra un sistema?-Unidad y contradieciones.-La razón mayor y la razón menor.-Unidad racional y unidad vital.-Interpretación fisiológica de la obra nietzscheana.

Pese a su afirmación: "la voluntad de sistema es una traición", hay en Nitzsche además de la unidad psicológica, artística, personal, de esti1o, unidad de direccion. Si, Como nos dice el psicomalista inspirado por él, Adler, hay una unidadgeneonsciontel èn todaryidamla tan manifiesta y notable del descendiente de los polacos condes Nietzky es también la doctrinaria de su obra, junto a la cual las contradicciones o las diversas etapas de su pensamiento tiene tan solo un valor adjetivo. Por esto aque1 lo de distinguir entre el Nietzsche positivista (hasta el año 82) y el místico (descle entonces) o entre la elapa negativa y la positiva (los mismos años) o aquello del Nietzsche trágico, el libre pensador volteriano y cien tifista y el del superhombre y Zarathustra tiene todo el convencionalismo de las clasificaciones.

Sucede que en un racionalista como Nietzsche para el cual lo primero no es siquiera el "ordre de coeur", pese a su afirmación de la superioridad de los sentimientos con respecto a los pensamientos, el haber considerado a la razón como la "razón menor" frente a esa mayor constituída por el cuerpo y sus instintos, todo sistema debería aparecérsele como una venta a esa pequeña razón cuyo predominio en Sócrates tanto 
detestó y tan funestas consecuencias hubo de traer - según él- para el porvenir de la cultura occidental.

Es por esto que si su obra no tiene unidad sistemática -esa unidad que reprochó a Schopenhauer - tiene en cambio unidad personal y vital que deviene por fin unidad racional y aún lógica. Si consideramos - con el glorioso antecedente de Pascal- esa lógica de que nos habla Ribot, con la que titula uno de sus libros y de la que parece haber sizo el exescolar de Schulpforta eximio representante: lógica del sentimiento -pero sentimiento nietzscheano, un extracto mental más cercano a los instintos que al corazón- la lógica de Nietzsche es lógica del sentimiento, de los instintos, de là voluntad, aunque no deja de ser por fir lógica del pensamiento, lógica racional. Esta unidad, por haber sido la de un excelso ejemplo del pensar con todas las potencias, tiene que no ser y ser más que pura unidad racional abstracta. Es con el "sprit de finesse" pascalino, con el que la podemos descubrir, en éste, que tuvo honda y vigorosa aquella unidad y de archlanalítico y gran psicólogo este espíritu.

Pero estudiando al filósofo Nielzsche debemos considerar su ambiente social e histórico así como su psicología y su fisiología sólo como un antecedente de su obra que tiene ya un valor independiente reclamado y obtenido por la gloria.

Se ha hecho la fisiología del filósofo y en cruel, inevitable reciprocidad contra quien denunció en su "Anticristo" las enfermizas raíces biológicas del cristianismo, se ha llegado a afirmar el desdichado privilegio de la exageración máxima en cuanto a la anécdota calumniosa pertenecerá a Nordau - que las obras de Nietzsche habían sido hechas entro una y otra estancia Jen ceasasude orates. Choyese sabe que son -todasanteriores al colapso que en las calles de Turín lo privó de la razón - de la pequeña - con la cual la grande, como gigante ciego, tampoco pudo hacer nada en esos años en que todavía permaneció en la tierra y entre los hombres. Pero se puede hablar de rasgos de precursora, premonitiva exaltación en el "Zarathustra" y más marcadamente en el "Ecce homo"; y encontrar antecedentes en la causa del fallecimiento del padre antes de los 40 años, rebländecimiendo cerebral, así fuera acelerado por una caída.

Quizá el mismo Nietzsche nos propone la mejor defensa de su caso y nos muestra como su obra no es manifestación más o menos inmediata de su fisiología, cuando nos habla de deber a la enfermedad una "salud mejor" y sobre todo cuando nos informa de la maravillosa claridad y lucidez de sus ideas en los momentos más críticos de sus padecimientos. No una obra de enfermo sino pese a una enfermedad, 
obra en lá que el orgullo y la resprnsabilidad como pensador sahían mantener fuera los elementos fisiológicos adversos y en todo caso capitalizarlos favorablemente. Se había apropiado a Salustio: "Increscunt animi virescit vulnere virtus".

\section{III.-LAS NUPCIAS}

" ${ }^{T} \mathrm{Te}$ amo! ¡Oh, Eternidad!" (Zarathustra, III, 16).

SUMARIO.-El eterno retorno.-Sus antecedentes.-El eterno retorno y la física moderna; idea del siglo XIX y contrario a las ideas del siglo XIX.-Cuatro interpretaciones diferentes de la vida humana: cristiana, materialista-mecanicista, oriental y nietzscheana.-Importancia del Retorno en la psicología y en la moral nietzscheanas.-Matrimonio de Nietzsche.-Horror y alegría del retorno.

El eterno retorno de todas las cosas, la idea cara a Heráclito y pre. sente mucho más lejos aún en las cosmogonias hindús de Kalpas y Mahakalpas, manvántaras y pralayas, la filosofía de la naturaleza del círculo, de la serpiente que muerde su propia cola, vuelve aún, hace este ciro pequeño retorno en el gran escalador de montañas en quien logrará las mayores consecuencias y repercusiones y en el que cobrará, como pensamiento madre, gran fuerza y esplendorosa magnificencia.

¿Es apenas una marca del siglo XIX que Nietzsche estuvo condenado a llevar, como afirma Heinich de Mann? ¿ Debemos suponer que son el energetismo y la entropial haya paisadona ses cuna superada idea científico-filosófica, apenas una curiosa característica del gran mostachudo? ¿O representa un ideal supremo del espíritu científico y del pensamiento del hombre? (como lo anota Ảbel Rel: la objetividad absoluta, un mundo bastándose a sí mismo y por tanto una idea de la cual puede alejarse el hombre en breves períodos de su historia pero a la cual tendrá que volver siempre).

Muy discutible científicamente -aunque hoy la física por atravesar todavía etapa crítica, es, en sus afirmaciones más fundamentales, aún, discusión - la idea del retorno fué considerada como cierta por el filósofo, que no dejó de combatir a mecanicismos en los que no aparecía como necesaria consecuencia. El mismo vértigo que a la imaginación produce el ejemplo de lo que es un kalpa ("si a una montaña del alto del Himalaya se le frotara suavemente un lienzo finísimo cada 100 años, el tiempo necesario para convertirla en un pedazo de tamaño no mayor 
que un quisante" es el que produce en el ánimo la idea del retorno. Es, también, por ello, una de las claves para la interpretación de la complicada psicología de Nietzsche - supergigante que no se contentaba con cargar el mundo, como un Atlas cualquiera, sino que se echaba a cuestas toda la eternidad. Horrible sólo para los espíritus mediocres la declara Nietzsche. Pero la mediocridad puede ser titánica -o supertitánicamente- vencida. El pastor de Zarathustra comienza por echarse al suelo y reohinar los dientes al saber que cada uno de sus actos ha de ser repetido con absoluta identidad de circunstancias por toda la eternidad y la inmensidad - "infinito relativo" - entre una y otra vida, equivale a nada. Pero quien no teme y desafía, arrostra y vive íntimamente esa, primero horripilante realidad del retorno - la alegría es más profunda que el dolor y quiere la más profunda eternidad- logra el máximo goce, flor de loto del descomunal estanque de la eternidad.

Esta filosofía nietzscheana de la naturaleza, que a veces dá la impresión de haber sido aceptada un tanto precipitadamente - la sirena del hallazgo científico del siglo a la que no pudo resistir el vehemente solitario que entonces habría desoído/su recomendación: "Resistir al pensamiento filosófico del siglo" - ha llegado al espíritu de Nietzsche en un instante de iluminación más que mística, pero ha tenido que defenderla - violento, celoso esposo de la eternidad - contra tendencias ya vigorosas de su tiempo que asignaban al mundo un fin.

Las interpretaciones de la vida pueden resumirse así:

1) Cristiana.PPrepaaración para otra yida superior; con criterio exclusivamente temporal en el cristiano medio o como un mínimo aspecto de realidad superior en ún cristianismo mâs elevado ("Sólo creen en la inmortalidad los que llevan aquí abajo una vida inmortal".-Tolstoi). De todos modos, esta opuesta a la otra "vida" que la encierra y de la cual solamente es prólogo -en el que está ya la obra-o superficie.

2) Materialista finalista.-A menudo cristiana desencantada - "Unica".

3) Oriental.-Una entre muchas diferentes: palingenesia.

4) Nietzscheana: una entre muchas que por ser idénticas constituyen su exacta repetición: una sola, eterna: el círculo.

Pensó el que dejó su pobre cuerpo de alienado en el siglo XIX para penetrar de modo tan violento y triunfal en el que vivimos, que el máximo sentimiento de responsabilidad se obtenía con el pensamiento del Retorno. Cada uno de nuestros actos lograba una seriedad e importancia junto a las cuales nada eran las que podrían derivarse de ser esta la única vida, o la decisión de la otra o una entre tantas. Al lado de la significación que adquiere cada uno de nuestros actos a la luz del Re- 
torno, el horror que pudiera derivar de la irrepetibilidad de los actos hu manos, de su unicidad o por lo menos de su irreversibilidad -para Nietzsche esto les quitaría casi toda su importancia- sería, comparado con el primero, un pequeño horror, un horror de segunda categoría al lado del máximo horror del pastor. Y ese es el mérito moral -en un sentido amplísimo que incluiría, que ante todo incluiría, cualquier inmoralismo- de la doctrina del retorno. Es todo lo contrario de una salvación en un trasmundo de felicidad con fracs y opíparos banquetes para los miserables. Es una desesperada consecuencia para con la verdad - la amante de este esposo de la eternidad, amante un tanto "usurpadora"- de quien pensaba que "la fe salva, luego miente". Verdad que con todo su horror puede ser, ella también, una salvación, sólo para un poseso del afán de conocimiento como Federico Nietzsche.

Y la invitación a esta verdad, que no estaba en el fondo de ningún pozo, más cubierta por una montaña de mentiras que habían devenido mentiras necesarias para la conservación y "salvación" de una especie de hombres que cada vez se empequeñecía más, no por obra de filiro de mago alguno más de sacerdote y civilización cristiana, fué aceptada. Y esta verdad del retomo fué la esposa legítima, nunca abandonada, de este Don Tuan del conocimiento. (Aún es posible señalar el lugar y casi el día de las nupcias: a comlenzos de Agosto de 1881 en los bosques de Sils María, no lejos de Surled al pie de una roca de aspecto piramidal, en dirección a Silvaplana).

Si la moral nos hace acometer las empresas más difíciles y si en algún sentido moral es esta Capacidad casi técnica, Casi este virtuosismo de

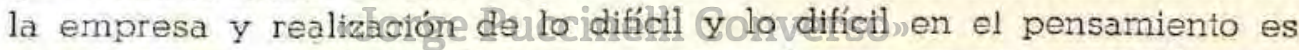
aceptar como verdadero lo que nos causa horror, en una ecuación contraria a la usual, lo más verdadero sería lo que más dolor nos causara. Hay que tener el exquisito temperamento moral, sin virtud cristiana pero con "virius" romana y el virtuosismo moral del inmoralista para alcanzar y aplicar este criterio.

Pero nos había propuesto también que no aceptáramos ninguna verdad que no llevara consigo alguna alegría - otra, entendemos, que la de su creación-hallazgo-. Probablemente pensaba que soportando tenazmente y sin rodeos, toda verdad la tenía. Y el fruto de esta angustiosa, máximamente angustiante verdad del retorno es la abșoluta y triunfál afirmación de la vida, pese a todo: Dionysios y su "alegre corona de rosas".

Sin embargo lo que se ha conservado con más vigor del "curita" (Nietzsche, cura, cuidado del mundo -esto es obvio, aún sin mencionar 
a Heidegger - más también enfermedad, enfermedad ya no del remedio más de la misma curación o curación por la propia enfermedad en una como homeopatía metafísica) lo que ha llegado más a lo íntimo de los hombres de este siglo es más bien la "hora cero", la vivencia angustiosa del nihilismo, lo que llamaríamos el problema si sólo afectara al intelecto. La solución dionysíaca en cambio, atrae pero desconcierta, seduce pero si no suena precisamente a falsa, por lo menos quizá sí a precipitada, a rápida. Nos invade la impresión de que la realidad o la verdad han sido violentadas por el genio. Estamos de completo acuerdo con el diagnóstico del médico Nietzsche - que como nuestro Carrión se inyecta eternidad para morir de ella- pero dudamos del medicamento, quizá por prejuicioso instinto alópata. En esta superación del horror, a través del horror, por la alegría, lo que encuentra el "humano, demasiado humano" es simplemente el pavor de una eternidad abismal, ápice y suma - sima- de todos los espantos.

"Soy un nihilista pero también todo lo contrario de un nihilista" nos dice en el Ecce Homo, y aunque el nihilismo es un momento de la historia del hombre - y aún de la historia occidental que miden siglos y no círculos cósmicos- hay un manifiesto paralelismo entre su hallazgo en el universo y su hallazgo en la historia: en el uno la más desesperante eternidad, el retorno, la "nada eterna", en el otro el nihilismo, nada psicológica y social, vacío en el fondo de las almas de los hombres y de los pueblos.

Pero el diagnóstico, el lácertado diagnóstico del médico Nietzsche, vale también como síntoma de su enfermedad $\mathrm{Y}$ de la de su tiempo. Enfermedad trasmitida - hereditaria, sólo quer de modo extrabiológico, cultural- al nuestro. Diagnóstico aún válido.

$\mathrm{Si}$, en general, el camino vale más que la posada -así sea esta la de la acción, expresión de la voluntad de poder - sentimos muy en espedial el atractivo del Nietzsche atormentado, nos convence más, nos trasmite mejor sus convicciones. Lo que se llama la "parte negativa" de la filosofía nietzscheana es por ello la menos cuestionable y puede que la simpatía hacia sus sufrimientos sea el puente por el que nos llegan - como en Jesús - sus verdades. 


\section{Mor a I}

\section{I.-EL PROBLEMA ANTES DE NIETZSCHE}

SUMARIO.-Primacía de lo ético en Nietzsche.-El inmoralismo como Weltanschauung, como método y como solución.-Nietzsche Salvador.-Nietzsche, Schopenhauer y el verdadero planteamiento del problema de la moral.-Caracterización nietzscheana de los fenómenos morales.-Historia crítica de la moral.-Nietzsche, hombre del siglo XIX.-Nietzsche y Descartes.-El cristianismo, sistema ptolemaico moral.-Falta de honestidad intelectual de Kant.-Fiegel y Nietzsche.

"Mi destino ha querido que yo fuera el primer hombre honrado". (Ecce Homo, Por que soy

Es indudablemente da Gonsideración dẹla Eticalo más original y destacado del pensamiento de Nietzsche. En repetidas ocasiones afirma el filósofo, la primacía de las valoraciones morales, que las valoraciones morales "están detrás de todas las otras" (V. de P. 258).

El "inmoralismo" nietzscheano, término en el que se ha tratado de sintetizar la posición de nuestro pensador, se puede entender como interpretación de la realidad, como métodó y como solución del problema moral; como consecuencia de la aplicación de este método sobre esa realidad aparecerá el "nihilismo" la grave, profunda y terrible realidad del "hombre moderno" - que es el como problema moral que tratará de resolver éste para quien lo moral no. existe- y del cual querrá, él también, "salvarnos" para lo cual ofrecerá una clave y aun, al aplicarla, una solución más o menos pormenorizada.

Nietzsche quiso también ser un Salvador sólo que de ningún modo a través de un falso mundo metafísico, contra el cual presenta una de las 
más violentas acusaciones en la Historia de la Filosofía. Su clave "Voluntad de Poder" y sus fórmulas "Trasmutación de todos los valores", "Superhombre" serán analizadas posteriormente.

Había observado Nietzsche que hasta él las valoraciones morales habían sido más bien sustratum oculto y rector que "problema" de la cultura. Schopenhauer había exclamado refiriéndose al inmanentismo "autónomo" de la moral kantiana: "Predicar la moral es fácil, lo difícil es fundarla" y había emprendido este intento logrando así la fundamentación de una moral —que Nietzsche había de rechazar y aún invertirintento que lo condujo a la supresión de la voluntad en el puro reinado de la idea. Esta antinomia Schopenhauer-Nietzsche en la relación ideavoluntad ha sido ya bastante destacada (p. ej. Simmel), pero nos parece mucho más importante aún la manera radicalmente opuesta que tienen los dos filósofos de encarar el problema. Mientras Schopenhauer trata de "fundar" la moral, Nietzsche se pregunta: ¿Por qué habremos de fundar "la moral"? ¿Por qué el espíritu había de resignarse a sólo una fundamentación? ¿Por qué no detenerla $y$ hacerle preguntas pidiéndole que modifique su soberbia existencia que, por lo menos desde Sócrates y Platón, influye decisivamente en los otros órdenes de valores? ¿Por qué no preguntarle: ¿Quién eres? ¿De dónde vienes? ¿Qué quieres? y también: ¿Eres?

Hace, pues, estas preguntas el filósofo y halla estas respuestas: "La moral es esencialmente el medio de crear algo y hacerlo duradero a costa de los individuos poporoles estavitud de los andividuos. Se comprende que la perspectiva de abajie arriba daría una perspectiva completamente distinta que la de arriba abajo (V. de P. 730).

1) "No existen acciones morales, éstas son completamente imaginarias. No sólo no son demostrables (Kant, el cristianismo) sino que son imposibles. Un error psicológico ha inventado un término opuesto a las fuerzas impelentes. Ateniéndonos a los contrarios debemos decir: sólo hay intenciones y actos inmorales.

2) El juicio moral se refiere a actos e intenciones libres pero no existen estos actos. El mundo al cual se pudiera aplicar esta distinción es imaginaria" (V. de P. 786).

"Las llamadas morales deben pues ser definidas como inmoralidades. Todas las pasiones se pueden deducir de la única voluntad de poderío, son sustancialmente iquales. Concepto de la vida: En un contraste aparente (entre "bien" y "mal") se expresan grados de poder, de instintos; a veces a una jerarquía bajo la cual ciertos instintos son frenados y puestos al servicio de algo: justificación de la moral: economía, etc." 
"¿Qué valór tienen nuestras valoraciones morales, nuestras tablas de bienes? ¿Qué se va ganando con su sostenimiento? ¿Quién? ¿En relación a qué? Respuesta: la vida. Pero, ¿qué es la vida? Aqui se impone la necesidad de un nuevo y más exacto concepto de la vida, mi fórmula es ésta: la vida es voluntad de poderío. ¿Qué significa una valoración moral en sí misma? ¿Hace referencia a otro mundo, a un mundo metafísico? (Como lo creía aún Kant, que precede al gran movimiento histórico). En suma, ¿Dónde nació? ¿O no nació? Respuesta: la valoración moral es una explicación, una especie de interpretación. La explicación misma es un sintoma de determinado estado psicológico y también de un determinado nivel de los juicios dominantes. ¿Quién interpreta? Nuestos afectos" (V. de P. 254).

"Bajo la denominación de Moral comprendo yo un sistema de valoraciones que se relacionan con las condiciones de vida de un ser" (V. de P. 256).

"Mi principal afirmación: No hay fenómenos morales sino meras interpretaciones morales de estos fenómenos. Esta misma interpretación es de origen extramoral". (V. de P. 258).

Las valoraciones morales "juegan en casi todas las impresiones de los sentidos. Por ellas colareamos el mundo".

"Nosotros ponemos los fines y los valores".

"La condición de la existencia falta hoy en el juicio moral" (V. de P. 260).

"Hay que estudiaßen lós pueblos cual es en cada caso el criterio y que es lo que se expresa con el". "Los filosofos moralistas griegos sentían con su polis".

"La moral es obra de la inmoralidad" (V. de P. 266).

"Dos tipos de moral: Una moral con la que se defienden los instintos sanos contra la decadencia creciente y otra con la cual esta decadencia se formula, se justifica y avanza".

Siendo indispensable estudiar el criterio - pero sobre todo "lo que se expresa con él"- de interpretaciones, en el fondo extramorales, de fenómenos también extramorales, en los diversos pueblos, Nietzsche emprende una "Historia de la Moral", sobre la que propone, además en un apéndice agregado al fin del primer libro de "La Genealogía de la Moral" que se hagan investigaciones utilizando las indicaciones lingüísticas y en particular etimológicas. Y si, como nos dice Croce, el interés de la Historia es siempre del presente - Bodin había expresado idea parecida en forma un tanto más restringida y al mismo tiempo extrema "La premiere utilité de l'histoire est de servir a la politique"- el interés de 
la historia de la moral emprendida por Nietzsche es de servir para la comprensión de la moral de su tiempo - de su espacio-tiempo-: la de la cultura occidental tal como se presentaba en el siglo XIX, en mucho la nuestra. A través de esa historia, acercarse al descubrimiento de la interpretación o interpretaciones subyacentes en esta moral y al de los estados fisiológicos, psicológicos y sociológicos subyacentes en estas interpretaciones, así como su relación con el estado psico-fisiológico y sociológico de este "hombre moderno", el europeo del siglo XIX.

Difícilmente separable de ella, pues el fllósoio de Röcken es -conscientemente - lo contrario de un "historiador objetivo", está la crítica de las valoraciones estudiadas. Su historia de la Moral es una historia crítica de la Moral, y ésta será la que tratemos de exponer.

El gran problema, que sólo on un sentido latísimo del término podemos llamar moral y que tan paradojalmente - pocas cosas en el análisis nietzscheano no son paradójicas- es ante todo resultado de la moral vigente, la espantosa realidad, el "mal" en esta filosofía que esta "Jenseits von Gut und Bose" y el problema que plantea, lo concretamos al igual que el propio Nietzsche, en el término "nihilismo". Pero este mismo mal habrá de ser etapa ineludible en el proceso de curación de este enfermo, el hombre moderno.

Nietzsche lleva en su obra la marca del siglo XIX, pero no precisamente por la idea del Etemo Retorno como equivocadamente lo afirma Heinrich Mann, sino por este enfoque histórico de las cuestiones filosóficas. Del mismo modo que elomarismo tral cque alguien propuso se le denominara historicismo materialista o histofficismo realista mejor que materialismo histórico- estudia la estructura, origen y desarrollo de las sociedades y sus diferentes formas para proponemos - desde ese determinismo que hizo a Unamuno llamar "profeta" a Marx - la del porvenir, así Nietzsche, estudia el origen y desarrollo de las distintas morales para también él ofrecernos una "moral del porvenir" paradojalmente derivada del inmoralismo e inmoralista también ella misma.

Se ha comparado la posición nietzscheana con la cartesiana. Como Descartes en el orden de la realidad y del conocimiento, así Nietzsche emprende esta otra revolución copernicana: la de la moral. "La tierra moral también es redonda" exclama sintetizando en esta opinión de exultante gozo, la riqueza del vasto panorama de la problemático de la Etica que aparece de su descubrimiento copernicano. ¡FFilósofos! ¡A los barcos!! grita en el "Gay Saber" destacando lo que tienen su pensamiento de más originalidad desde el punto de vista filosófico: análisis y crítica de los valores morales imperantes y creación y afirmación de nuevos 
valores morales, que son posibles y que serán superiores a los abandonedos. El gálico padre de la filosofía moderna no había extendido si "omnibus dubitandum" a las propias normas morales entonces vigentes, que guerdó como es sabido en una cabaña - no importa si provisionalque escapó a la duda. Y en su desarrollo posterior la filosofía siguió tratando casi como terreno vedado la moral - ya no una cabaña; un cerrado coto de caza. ("Se consideraba como inmoral hacer estas averiguaciones"). No se había afrontado la moral toda como un gran problema. No se había problematizado la moral.

Esta es la gran obra filosófica del inmoralista Nietzsche, la parte más destacada y la verdaderamente central de sus hallazgos, tantos y $\tan$ ricos en perspectivas y fecundos en desarrollos. "La crítica - decía Nietzsche- nunca es dirigida contra el ideal mismo sino sólo contra el problema de averiguar de dónde procede la contradicción contra él mismo, de por cué aún no se ha alcanzado o no es demostrable".

Ha sido considerado, así, el inmoralismo nietzscheano (Dr. A. Stern "Nieizsche et la Philosophie do la violence du vinghtieme siecle") ante todo como un método, como el inevitable método de quién necesita mirar la moral por debajo de sí para poder investigar de modo cabal, con la amplitud de miras indispensable - diriamos "con objetividad científica" si no recordáramos todo lo que Nietzsche dice contra la objetividad $y$ en particular contra la objetividad científica - el campo moral. Pero si tenemos derecho a hablar del inmoralismo "comme methode de la recherche morale" es igualmente acertado el término para describirnos la realidad inmoral -o extramoral- de los llamados fenómenos morales y más aún para denóninfreal lesntenidb fositivor des la moral del inmoralista Nietzsche, historiador, crítico, destructor y creador en moral.

La referencia más constante del Copérnico moral había de ser lógicamente al sistema ptolemaico moral: a la moral cristiana. "Un mundo que podríamos venerar, que es apropiado a nuestros instintos reverenciosos, que según parece continuaríamos teniendo por la dirección de los individuos y de los grupos: esta es la concepción cristiana de la cual procedemos todos. Por un aumento de perspicacia, de confianza, de sentido científico (y también por un instinto de veracidad de la más alta dirección) esta interpretación se nos ha hecho cada vez más imposible (V. de P., 233). Sin embargo "no hemos de pensar con desprecio en aquello que durante veinte siglos disciplinó moralmente nuestro espírtu" $^{\prime \prime}$ (V. de P., 267). Repudia, sí, con vigor, Nietzsche, a los que criticando el origen de las valoraciones morales creen en ellas, tanto como si fueran cristianos. Esta creencia en la moral sin un Dios que la sancione le 
parece una ingenuidad: "El más allá es absolutamente necesario cuando se quiere conservar sinceramente la fe en la moral". (V. de P., 253).

Repudiaba Nietzsche de Kant, su inmediato gran antecesor, el haber "utilizado todos los medios por los cuales la reflexión y la crítica pue den ser paralizados en este terreno"- (V. de P., 254) y, sin embargo, por una argucia -quizá porque Lampe, su criado, no era feliz con la sola razón pura, como lo había observado Heine- "le mantenía y exaltaba por otra vía". Por ello es que nos dice "El kantismo es una filosofía de las puertas traseras". "Del hábito de las autoridades absolutas ha nacido últimamente una necesidad hacia las autoridades absolutas, tan fuerte, que aún en épocas críticas como la de Kant, se muestra superior a toda necesidad crítica y en cierto sentido se apodera del trabajo del entendimiento crítico y le hace servir a sus fines" (V. de P., 412), "el mismo Kant, en toda su inconciencia de esta corrupción de los pensadores, ha tratado de constituir científicamente el concepto de razón y hasta inventó una razón para prescindir de la razón a ratos, a saber las necesidades del corazón cuando hablan la moral y "el deber" (V. de P., 413). Llamará también al gran chino de Koenigsberg "Fanático moral a lo Rousseau y completamente in-histórico" (V. de P., 382) por lo que "pertenece enteramente al siglo XVIII" (V, de P., 96).

"El criticismo kantiano: el intelecto se niega a sí mismo el derecho tanto para la interpretación en aquel sentido como para la renuncia a la interpretación en aquel sentido. Se contenta con un aumento de confianza y de fe, con una renuncia tacleda demostrabilidad de esta fe, con llenar esta laguna con pn ideal (Dios) incomprensible y superior" (V. de P., 253). Todavía manteniéndose en alguna forma dentro de la apreciación filosófica, ya que tanta importancia tienen para Nietzsche lo fisiológico, agrega: "Si Kant, por ejemplo, decía "Hay dos cosas eternamente venerables" (final de la "Razón Práctica") hoy podríamos decir: "La digestión es más venerable todavía", pero su impaciente mordacidad no sabe contenerse y llega a decir "Kant ha sido una especie de espantapájaros". (V. de P., 127).

Lo que en primer lugar rechazaba Nietzsche de Kant era "esa falta de honestidad intelectual" que de "una corriente subterránea de valores cristianos" hacía un imperativo categórico, creaba "esa otra razón" de que nos habla en párrafo ya mencionado.

Consideraba por otro lado Nietzsche la identificación en Hegel, de la moral y el mundo metafísico con la historia y el éxito como una posición más cercana a la suya propia, pero todavía de ninguna manera un correcto planteamiento del problema moral como tampoco lo, había sa- 
bido hacer Schopenhauer. Había en estos filósofos demasiada fe en la moral.

Nietzsche decía que "La fe en la moral no es ninguna prueba en favor de la moarlidad: hay casos y el de los filósofos es uno de ellos en que tal fe es simplemente una inmoralidad". "Nosotros ya no creemos como ellos (Kant, Hegel) en la moral y por consiguiente no tuvimos que fundar ninguna filosofía para fundamentar la moral". "Tanto Kant, como Hegel, como Schopenhauer, tanto la actitud escéptico epojística, como la histórica, como la pesimista, son de origen moral. No conozco a nadie que se haya atrevido a una crítica de las valoraciones morales, y las escasas tentativas de llegar a una historia del origen de estos sentimientos (Como la de los darwinistas ingleses y alemanes) tan poco me gustaron que pronto les volví la espalda". (V. de P., 410).

\section{II.-HISTORIA DE LA HISTORIA DE LA MORAL}

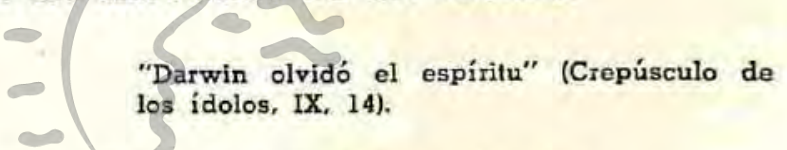

SUMARIO.-Las primeras tentativas: Los utilitarios ingleses, Spencer.-La obra del Dr. Ree.-Antecedente darwinista de estas tentativas.-Nietzsche y Dar win - sus diferencias-: Relativismo del concepto de utilidad, circunstancias exteriores o fuerza interna: Malthus ol anaturaleza, conservación de la vida o vida, hambre o instinto de apropiac:ón. Funciones orcánicas o voluntad de poder.Clases sociales en el cuerpo humano.PuCCinelli Conversom

La tentativa histórica del propio Nietzsche la encontramos en la "Genealogía" y en numerosos párrafos sueltos de sus obras. Aunque no cometió el grosero error de identificar la historia con la crítica de la moral, nos hace ver que la primera prepara un estado de ánimo crítico y es por ello que lo que él hace es Historia crítica de la moral, como ya anotamos.

Pero antes de pasar a la nietzscheana Historia de la Moral, hagamos así sea una breve Historia de la Historia de la Moral; la de los ingleses influídos por el darwinismo a los que ya nos referimos; la de los abiertamente darwinistas y la de ese darwinista alemán en el que nos atrevemos a imaginar que pensaba Nietzsche al pluralizar; el Dr. Pablo Ree, judío, amigo suyo del que se separó violentamente por razones íntimas después de una larga amistad. Parece haber tenido alguna influencia en el gran solitario - muy exagerada en la obra de Lou Andreas Solomé 
sobre Nietzsche- sin que éste nunca hubiera olvidado en sus relacicnes con Ree su propia superioridad. En la villa que esa maravillosa mujer Malwida von Meysemburg tenía en Sorrento, una especie de convento laico - propósito que siempre habia acariciado Nietszche y para el que había tratado inútilmente en otro tiempo de ganar algunas amigos-, habían convivido por espacio de largos meses de pláticas sobre las más diversas cuestiones, lecturas, meditación y estudio. Estaban entonces interesados en los mismos problemas. Ree había compuesto durante su estancia allí (oct. 1876-abril 1877), un pequeño libro "Der Ursprung der moralischen Empfindungen".

Pero las primeras tentativas fueron las de algunos pensadores ingleses, pensadores a los que Nietzsche al igual que su maestro Schopenhauer tuvo en muy poca estima: "los incansables e incontables utilitarios ingleses que avanzan y reculan pisando y repisando las huellas de Bentham". "En estos moralistas... se infiltró el antiguo vicio inglés que se llama "cant" y que es hipocresía moral, aunque con máscara científica". En resumidas cuentas pretenden que la moralidad inglesa sea reconocida como superior a las demás porque dicen que con eso se hace un gran servicio. ¿A quién?, da la humanidad? No. ¡A Inglaterra! "Son individuos modestos y mediocres estos utilitarios ingleses, como fastidiosos nunca podemos alabarlos bastante. Deberíamos animarlos hasta en verso: "Yo os saludo joh valientes catreteros! ¡Cuanto más tardos mejor! ¡Ca. da vez más sucia la cabeza y las piernas sin entusiasmo ni alegría! Irremediablemente mediactes, sin Genlo पि sirgracla". Estos "valientes" sostuvieron que los conçeptos übuene"l y C̈eltruista"of fueron creados por aquellos a quienes beneficiaban determinadas acciones. Después se olvidó la razón originaria de las alabanzas pero se mantuvieron estos nombres. Bueno es lo que fué útil y cuya utilidad se olvidó.

Encuentra Nietzsche más sensata, aunque sin aceptarla tampoco, la opinión de Spencer para él que "bueno", "útil" y "oportuno" representan la sanción de la historia precisamente a sus experiencias inolvidables sobre lo útil e inútil, sobre lo oportuno e inoportuno. (Bueno lo inolvidablemente útil).

Ree que aceptaba las afirmaciones darwinistas fundamentales elaboró a base de ellas, durante la mencionada estancia en Sorrento (oct. 1876-abril 1877) ese pequeño libro sobre el origen de los sentimientos morales. Sus opiniones son las siguientes: En el origen de nuestros juicios sobre bien y mal hay un instinto egoista (de conservación y vanidad) y uno altruista que quiere el bien o evitar el mal de otros; estos 
instintos se encueniran incluso en los animales, si bien el altruista en una forma más reciente y débil.

Nietzsche rechaza de Ree esta distinción entre actos egoístas y altruístas. Lo importante de la moral es que asegura por medio de la creencia la unanimidad, sin la cual la sociedad perecería. Nietzsche hace la psicología de los instintos gregarics ante los cuales una acción individual renovadora toma el aspecto de un crimen: Desde "El origen de la tragedia" hablaba de lâ "doble prehistoria del Bien y del Mal", idea que desenvolverá cumplidamente bastante después, en la "Genealogía".

Siendo las anteriores concepciones resultado - directo las mencionadas en primer lugar y un tanto menos la de Spencer- de la posición darwinista, la discrepancia de Nietzsche de la biología del gran evolucionista inglés, nos servirá para comprender la de la "Genealogía de la Moral" nielzscheana respecto de la darwinista:

1). - Contra el concepto de utilidad darwinista Nietzsche dice que la utilidad de un órgano no explica su formación. Durante el tiempo demasiado largo durante el cual una propiedad se forma, no tiene utilidad. 2).- Además, ¿qué quiere decir "útil"? Slempre que se nos hable de utilidad debemos preguntar, ¿con relación a qué? Lo útil para la conservación podría ser nocivo para la fuerza y esplendor. Lo que es útil para la conservación del individuo, para la fijación y duración de lo que evoluciona, podría ser nocivo para la evolución. Además órganos degenerados podrían tener la suprema utilidad de estimular a los otros.

3).- "La influencia de las circunstancias exteriores es exagerada en Darwin de un modo absurdo L Cdice Niefzsche, ESP" esencial en el proceso vital es precisamente la enorme fuerza plasmante, creadora de formas del interior al exterior, que utiliza, disfruta las circunstancias exteriores. Las nuevas formas creadas partiendo del interior no están hechas para un fin" Este párrafo es de una importancia decisiva. No es que haya un fin que no es la utilidad sino que no hay tal fin, por lo menos precediendo al acto. Todo lo que existe cambia de fin porque una fuerza mayor se lo apropia, lo que se considera como "útil" depende completamente de la intención del "para qué", la intención, la meta, es a su vez dependiente del grado de poder, por esto el utilitarismo no es una base explicativa sino una doctrina secundaria y de ninguna validez para todos. (V. de P., 724). "Se debe liberar completamente de los fines la absoluta necesidad" (V. de P. 787). "Mi idea es que faltan los fines y éstos deben ser individuales. Vemos la tendencia general: cada individuo es sacrificado y sirve de instrumento. Id por las calles y encontraréis pu- 
ros esclavos". ¿Dónde van? ¿Qué quieren? (V. de P., 69). Toda nueva determinación trae una nueva interpretación, un nuevo fin. Spinoza aparecerá como el gran antecesor de esta opinión. Pero el punto de vista nietzscheano diferirá del de aquél. Ni "fin" ni "causa". El ataque de nuestro filósofo al "causalismo" es particularmente vigoroso.

4).-Util en el sentido de la biología darwiniana significa lo que en la lucha con otros seres se demuestra ventajoso. Pero el sentimiento del crecimiento, del devenir más fuerte es, para Nietzsche, el primordial, abstrayendo de él la utilidad en la lucha. De este sentimiento nace precisamente la voluntad de lucha. Además, la "Struggle for life" le parece excepción. El aspecto conjunto de la vida no es la indigencia sino la riqueza: No se debe confundir a Malthus con la naturaleza.

5).-Los fisiólogos en general deben considerar la conservación en menor importancia de la que le han dado. Esto es extensible a Spinoza y a la voluntad de perseverar en el propio ser. Sólo a un tuberculoso como él, decía Nietzsche, se le pudo ocurrir ponerla en lugar tan decisivo en su sistema. "Ante todo lo que vive quiere desplegar su fuerza: la "conservación" es solamente una de/las consecuencias de ésta. Cuando el protoplasma absorbe de modo insensato más de lo que necesita para su conservación y a consecuencia de ello no se conserva, sino se disgrega, vemos cómo en esta actividad primigenia, lo primordial es un instinto que se manifiesta en lo contrario de la conservación. Aunque tampoco debemos considerar este acto como "altruismo". Es un arrojar lastre, expulsar materia inútil. Ni conservación ni altruísmo: Rechazo de lo inútil, la escisión de un protoplasma en dos se verifica cuando la potencia no basta parardomina a la propiedad incorporada. La generación es resultado de una impotencia.

6).-El Hambre tampoco es el "primun mobile". Debemos considerarlo como una forma especializada y más tardía del instinto, como una expresión de la división del trabajo puesta al servicio de un instinto superior que la domina. Significa sólo una voluntad de poderío que no es ya la dueña. Sólo posteriormente deviene una necesidad de reparar las pérdidas. Cuando la célula proyecta seudópodos y palpa alrededor de sí، manifiesta una voluntad de poder que no puede expresarse sino cuando encuentra resistencia. La apropiación y la incorporación son ante todo voluntad de adueñarse, de dominar. La nutrición es sólo derivada, lo original es el apropiarse de algo $(651,652,656,657)$.

Parece contradecirse el filósofo cuando nos dice primero que hay un desplegar fuerza y después que la generación es resultado de una impotencia. Observando más atentamente veremos que no hay tal con- 
tradicción. En el primer acto de absorción de un elemento extraño hay una inútil y peligrosa manifestación de voluntad de poder, de crecimiento, cuya consecuencia es este segundo momento: la disgregación, la división en dos células, la generación, consecuencia de la impótencia en dominar a tan vasta extensión, movimiento siempre dirigido por una voluntad de poder que busca sus límites para dominar, separando de sí a lo no dominable e inútil. Manifestaciones sin embargo como "adolescente" la una y como "viril y consciente" la otra de un mismo instinto de dominio. La generación es pues derivada. En su origen es esto - nos diría después el mismo Nietzsche- "donde una voluntad no basta para organizar todo lo que nos hemos apropiado entra en vigor una contra voluntad, la cual se encarga de desembarazarse de lo superfluo" (V. de P., 651, 652, 653, 654, 657).

7).-Para Nietzsche las funciones orgánicas son especializaciones de la Voluntad de Poder (V. de P., 658).

8). - Considerando después ya no una célula sino el cuerpo, en particular el cuerpo humano, Nietzsche ve en él "Una aristocracia" con una esclavitud y una división del trabajo: el tipo más elevado sólo resulta posible mediante el envilecimiento de un tipo más bajo y la reducción de éste a función".

Es en la diferente interpretación de los fenómenos biológicos donde encontramos la raíz de la opasición de Nietzsche a la historia de la moral darwinista 0 inspirada en el darwinismo. Si bien alentó a su amigo Ree a que prosiquiera len estas inyestigaciones, no debemos ver en ello una coincidencia en las conclusiones, sino en la disciplina misma, en la historia de la Moral, Julgecieneicide la Motaletam joven, novicia y grosera como múltiple fino y refinado era entonces en Europa el sentimiento moral". (Más allá del Bien y del Mal, 186). Disintiendo de Ree aparece sin embargo callando cortésmente el nombre del autor en "El viajero y su sombra".

Refiriéndose a las conclusiones de los historiadores de la Moral darwinista, Nietzsche atacaba.su antihistoricismo que los hacía incurrir en contradicciones: Por que si las actos útiles se hubieran olvidado ¿cómo habrían subsistido la especie y las saciedades?

Spencer le parece, por lo demás, un representante tipo de lo que llamamos (hace la observación: a feo hecho, feo nombre) "misarquismo" y acoge la acusación de Huxley al mismo autor: nihilismo administrativo. Pero, agrega, "es mucho más que administrativo" (Genealogía II, 12). Es una corriente que domina a la ciencia natural -biología y fisiología en particular- del siglo XIX, corriente que olvida la voluntad de poder, hon- 
dura y clave de la vida, y por eso tiene qeu caer en ingenuidades como poner la adaptación en primer lugar.

Haciendo la psicología de estos historiadores, ve a bajos instintos haciendo historia (Si no. ¿Por qué esa preocupación por la "parte honteuse" del hombre?); su mordacidad a veces tan insultante los llama "viejas ranas viscosas e importunas" que "estudian el alma al microscopia". Son, sin embargo, esos ingleses en los que siempre aparece el "platter empirismus", $\tan$ insoportable para su maestro Schopenhauer y que él desprecia, sus precursores en esta disciplina, la historia de la Moral.

\section{III.-PREHISTORIA DE LA MORĀL, SEGUN NIETZSCHE}

"Los sentimientos de valor son distintos arriba que abajo" (Voluntad de Poder. 994).

SUMARIO.-Las dos morales.-Apreciación noble y apreciación plebeya.Apreciación sacerdotal.-El judaísmo y el cristianismo, su corona.-La moral: acción creadora o reacción resetinda.-Criterio: actiyidad o pasividad constituyen la feliciclad.-Bueno y malo en las dos morales. Prejuicios gnoseológicos do la concepeión moral vigente denunciacios por Nietzsche. Determinismo nietzscheano de la fierza.-Mendacidad. cualidad sacerdotal-Rectificación a Dante.-Roma y Judea.-Antisemitismo y prosemitismo de Nietzsche.-Amos y esclavos.

Nietzsche como Hegel ("Phenomenologie des Geistes") ve en la lucha a muerte que crea entrelos hombres la diferencia entre maestro y esclavo, el hecho social primitivo. Es una mayor especificación del "bellum omnes anti omnes" de Hobbese Es Talafirmaerón marxista de la historia como historia de la lucha de clases, pero sí también clases en Nietzsche no económica sino vital, la raíz de la lucha y lo económico una de sus manifestaciones. Por lo demás el germanismo de nuestro filósofo ve en el abolir la explotación del hombre por el hombre una necedad tan soberana como abolir la vida misma, que es voluntad de poder que se manifiesta en dominio, opresión, aplastamiento. (Más allá del Bien y del Mal, 259).

¿Qué método usará Nietzsche para hacer la crítica histórica, historia crítica de la moral? Volviendo al revés, la afirmación bíblica "un árbol se conoce por sus frutos" afirmará: "Es un fruto por el cual conozco yo el terreno en que crece" (V. de P., 257). Las morales son justificadas vitalmente, deben considerarse como síntomas y signos de expresión en los que se revelan procesos fisiológicos, así como la conciencia de condiciones de conservación o de crecimiento" (V. de P., 258). 
Es "en la conciencia de la superioridad y de la distancia, en el sen. timiento general fundamental durable $y$ dominante de una raza superior imperante en oposición a una raza inferior, a un bajo fondo humano en donde se encuentra el origen de la antítesis bueno-malo". El lenguaje mismo al que pertenecen éstas y las demás denominaciones es un acto de autoridad. En el primer momento lo bueno no se relaciona en absoluto con lo "altruísta". "Buenos" es el nombre que los nobles se dan a sí mismos.

Nietzsche encuentra que estas afirmaciones son el resultado de sus indagaciones lingüísticas y en particular etimológicas. El "sabio", el profesor de filología que a los veinticuatro años ocupó una cátedra en la Universidad de Basilea sirve al filósofo, historiador de la moral.

"Bueno" en las diversas lenguas aparece primero como "distinguido" y "noble" en el sentido del rango social. Esta es la idea madre de donde se deriva después la de bueno y sufre un desarrollo paralelo a la que transforma "vulgar", "plebeyo" y "bajo" en "malo". Es por las etimologías de las diversas lenguas que nos llega el matiz por el cual los nobles se sentían de rango superior: No siempre el poder —aunque sí en la mayoría de los casos- sino a veces las manifestaciones externas del poder: "arya" denota riqueza; Eovi.os significa el que es real, el que existe y después el verídico (por oposición a la mendacidad de la plebe como lo anota Theognis de Megara al que Nietzsche dedicó uno de sus trabajos filológicos juveniles), señala por último al bueno, bravo, valiente, generoso; жa\%os y detios y subrayantla cobardía, por oposición al multívoco a yaios. "Malus" trae suj origende $\mu \varepsilon 2$ as que designa el color obscuro de las razas vencidas. El alemán "schlecht" que viene de "Schlicht", simple, designó hasta la guerra de los 30 años al hombre de la plebe. En el dialecto gaelico la voz "fin", término distintivo de la nobleza que en último término quiere decir bueno, noble, puro, significa en su origen "cabeza rubia": nos habla de los dominadores arios y los dominados prearios a cuyo color de tez e instintos se refieren los vocablos anteriores.

Esta idea de la "bestia rubia" primitiva parece tomada del libro "Societé animales" de Espinas que Nietzsche había leído por entonces. Miquiavelo y Gobineau lecturas predilectas del filósofo, particularmente el primero, de quien se alejó mucho menos que del segundo, han influído o corroborado las apreciaciones que hace. El hecho histórico que parece haber tenido en cuenta es la prehistoria de Esparta.

"Buonus" viene de "duonus" (cuyo origen estaría en due-llum y bellum) significando el carácter guerrero de esta nobleza. "Gut" y "goe- 
tliche" (bueno y divino) harían relerencia a un pueblo "Goth", pero primitivamente a una nobleza.

Estas presuntas etimologías han sido muy combatidas, en especial por el gran filólogo Marcel Breal, el autor de la "Semántica", pero no parece haber razón para un menosprecio de la labor de Nietzsche en este orden, asi se equivocara como parece que se equivocó, por lo menos en las tan importantes de "buonus" y "malus". Su hipótesis ha permitido descubrir otras muchas etimologías que no conoció y que la confirman; así: sin mencionar "villano" habitante de la villa —evaluación primero social y después moral - se puede considerar el germánico "adal" de "ath " trasmitido por los ascendientes y "frevel", orgulloso, soberbio primero y después, "sacrilego" que delata una apreciación plebeya.

La otra fuente de las evaluaciones morales que debemos distinguir de la anterior es la sacerdotal, lo bueno y lo rnalo, tuvieron entonces su origen en el puro e impuro que en un sentido nada simbólico se refería antes bien bastante groseramente al que observaba los hábitos de limpieza de esa casta, debidos a sus funciones especiales. Caracterizaba a estos sacerdotes su hostlilidad a la accion, el "empollar los sueños". El hombre se hace animal enfermo e interesante en ella que proporcionará a la especie humana sus atributos superiores: la profundidad y la inclinación al mal.

Hay un contraste entre estos dos modos de apreciación: Una poderosa arquitectura corporal, una salud floreciente y guerras y aventuras y diversiones: caza, baile, juego y ejercicios violentos caracterizaban la superioridad de los unos y eran repelidos por los sacerdotes, de cuyo lado es-

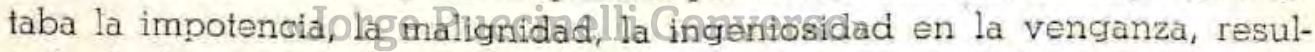
tado de la impotencia, que verdaderamente ha impedido que fuera $\mathrm{m}$ sípida la historia de la humanidad. Esta venganza esencialmente espiritual ha estado representada en la historia por los judíos.

Es con los judíos, con la sacerdotal moral judía que comienza "el levantamiento de los esclavos en la moral": únicamente los miserables, los pobres, los impotentes son buenos, los que sufren, los necesitados, los enfermos, los deformes son los únicos benditos de Dios, a ellos únicamente pertenece la felicidad eterna. For el contrario los nobles, los poderosos desde la eternidad son malos, crueles, insaciables, impíos y eternamente habrían de ser los réprobos, los malditos, los condenados.

Es el sacerdote judio quien lleva a cabo por primera vez esta tras. mutación de todos los valores. Es en este segundo momento, decadencia del ideal aristocrático y ascenso del ideal de rebaño, en que se hace la equiparación bueno-altruísta-desinteresado. 
Esta rebelión de esclavos en la moral tiene su comienzo cuando el rencor por sí mismo se hace creador y productor de valores, ofreciendo una compensación en una venganza imaginaria. Una reacción, un jno! a la moral de los señores es el acto creador. Nace de un mundo rico y fuerte que le es opuesto y externo. La apreciación de valores de los amos al contrario nació espontáneamente y sólo buscaba a su antípoda para afirmarse a sí misma. El concepto negativo es en esta apreciación un "pálido contraste nacido tardíamente". Si hay falseamiento de la esfera opuesta menospreciada es bien distante de la violenta desfiguración del odio reconcentrado y del rencor impotente. Hay matices casi benévolos para establecer la diferencia entre la nobleza griega y el bajo pueblo en los que el desdichado es el predominante $(\delta \varepsilon \iota \lambda .05, \delta \varepsilon i \hat{\lambda} \iota \iota$ s

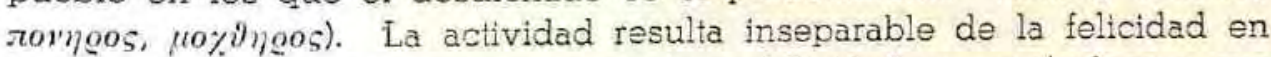
los señores que no necesitan construir su felicidad comparándose a sus enemigos y dominándose a sí mismos, como lo hacen todos los hombres del rencor. Sólo para éstos la felicidad es la paz, el Sábado de Sábados (Augustín, Obispo de Hipora). Son francos, ingenuos, leales consigo mismos mientras que los hombres del rencor, almas ambiguas, esperan, se humillan, la prudencia se hace mayor y más decisiva y son incapaces de esa espontaneidad entusiasta para la cólera, el amor, el aprecio, la gratitud, la venganza misma de los distinguidos que si pueden ser rencorosos, no tienen veneno en fu rencor. "No poder tomar en serio a sus enemigos, a sus desdichas y hasta a sus delitos" es señal de esta superabundancia de frerza plástica reorganizadora de los señores. Se desembarazan de una sola sacudida de muchas miserias que en otros se instalan permanénteninenteucsilfuena posiblerenda tierra "el amor del enemigo" sólo ellos podrían tenerlo, ellos que respetan y elevan a su enemigo, nos dice el filósofo.

Vemos que el malo de la moral de maestros y el malo de la moral de esclavos no están opuestos a un único tipo de bueno. "El perverso de la moral rencorosa es precisamente el bueno de la otra". Porque este bueno, noble que "inter pares" se contienen en los límites de su rango, alli donte comienza el extranjero vale un poco más que fiera desencadenada, retorna a la simplicidad de conciencia de la fiera, se transforma en monstruo triunfante. En el fondo de estas razas aristocráticas es im. posible no reconocer a la "bestia rubia" vagabunda en busca de presa y matanza. Pero en cualquier aristocracia romana, árabe o japonesa tanto como en la germánica podemos apreciar las "voluptuosidades de la victoria y de la crueldad". 
Contrastan estas aristocracias con "el hombre domesticado" -en el que anidan degeneración, enfermedad, fatiga, senilidad, mezquindaden el que se quiere ver el sentido de la historia.

Es necesario el hombre al que por temérsele pueda amársele. La humillación y la nivelación del europeo ocultan nuestro mayor peligro, "este espectáculo deja el alma fatigada".

"Al cesar de temer al hombre hemos cesado también de amarle, de venerarle, de esperar en él, de querer con él".

Sólo por las seducciones del lenguaje y los errores de la razón cristalizados en él es que distinguimos entre la fuerza y el "sustraturn" de la fuerza, neutro y libre para manifestarla o no. Pues no hay "ser": el actor está unido al acto. El encanto del lenquaje se hace presente aún en la ciencia y decimos que la fuerza produce tal y tal efecto y desdoblamos así el fenómeno en "causa" y "efecto de la causa".

Por estos errores de una teoría del conocimiento no por extendidos menos ciertamente errores, es que se cree en un libre arbitrio y se pide al fuerte que se haga débil olvidando que la resultante de una determinada cantidad e fuerza no puede sef otra gosa que "la misma cantidad de instinto de voluntad, de acción". (Genealogía de la Moral I), Jules Gaultier habla del "determinismo de la fuerza" en Nietzsche.

Es lo cierto que dentro de la moral de los esclavos hay esta afirmación: "Nosotros los débiles semos decididamente débiles, nos guardamos por tanto de hacer todo aquello para lo cual no somos suficientemente fuertes. En el fondo se trata de una prudencia de calidad muy inferior, de la que hasta un insecto pose. Gracias a un impotente engaño de si ha tomado las pomposas apafienclas den virtudp que sabe esperar, que renuncia y enmudece" como si la debilidad misma del débil —es decir, su esencia, su actividad, toda su realidad única, inevitable, indeleblefuera una realización libre, algo voluntariamente escogido, un acto de mérito. Son los débiles los que por un instinto de conservación y afirmación de sí tienen fe en el "sujeto" dotado de "libre arbitrio". De aquí que el "alma" haya permanecido como artículo de fe inconmovible.

En una audaz rectificación a Dante que había colocado sobre el infierno el rótulo "A mí también me creó el amor eterno" dice Nietzsche que sobre la puerta del cielo está el "a mí me creó el odio eterno".

Nos ofrece como símbolos de las dos morales Roma y Judea. Los romanos, los fuertes y nobles hasta un punto tal como nunca se ha visto hasta hoy sobre la tierra y los judíos "convictos de odio hacia el género humano" pueblo nacido para ser esclavo según Tácito (Más allá del
Bien y del Mal). 
Ha sido en párrafos como los anteriores en que han querido insistir los neonietzscheanos de la Alemania nacionalsocialista para presentarnos un Nietzsche antisemita. Como reacción otros estudios basándose asimismo en numerosos pasajes nos han mostrado un Nietzsche prosemita y antialemán: Stern, Barrenechea, H. Mann, Lefebvre entre ellos. Los párrafos citados por los dos lados son auténticos. Y es que Nietzsche en apasionado análisis imparcial de alemanes y judíos es antisemita y prosemita y antialemán y proalemán por cuanto nos demuestra con igual lenquaje extremo méritos y defectos de ambos. La tónica varía según los libros: La "Genealogía" es de los más proalemanes y antisemitas. "Ecce Homo" de los más filosemitas y duros con Alemania y los alemanes.

Resultado de la historia - y prehistoria - de la moral es la tipología moral de Nietzsche: La moral de los amos, de los nobles, de los señores y la moral de los esclavos, que encuentran su expansión y predominio por medio de la moral sacerdotal que no es sino su "espiritualización". Un modo más refinado, sutil, peligroso, tentador, "judaico" de la misma.

\section{IV,-FILOSOFIA DE LA HISTORIA}

\section{"Hay mil senderos que jamás fueron hollados. Bibliote de la vida" (Zarathustra I. 22. I).}

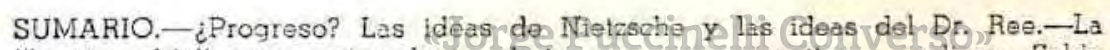
"bestia rubia" como antecedente gterioso y como arquetipo a realizar. - Saldio farvorable del judaísmo.-Error de Papini,-Nietzsche niega el progreso y afirma su posibilidad.

Estas dos verdaderas "estructuras históricas" de la moral se oponen a las de Ree, que las consideraba de origen animal y si más tardía la altruista, más tardía pero animal, prehumana y con antecedentes en los mismos fenómenos de la biología unicelular. Y si la del Dr. Ree tieng algún parecido con la historia de la moral nietzscheana, la valoración que hace de los fenómenos altruístas, los mejores pero tan pocas vecej realizados, tan históricamente inexistentes, es absolutamente opuesta a la de Nietzsche. Son, además de posteriores, históricamente falsos, reactivos, inferiores. Se querría aplicar la dialéctica hegeliana y decir que a la tesis "moral señorial" corresponde la antítesis "moral de esclavos". La síntesis buscada sería la moral del mismo Nietzsche en la que no debemos ver como algunos apresurados y tendenciosos intérpretes del fi- 
lósofo turingio una simple vuelta a la "bestia rubia" a la agresivamente feroz aristocracia primitiva, a esta ingenua crueldad bárbara que si despierta en él alguna exclamación admirativa es sólo como por oposición a la tabla de valores reinante y con un sentido polémico, para así acercar la sintesis - "negación de la negación" - a la tesis, a la "afirmación" primitiva. Pero de un modo muy particular, de ningún modo para confundirlas. Que si Nietzsche habla del "inconveniente de los estudios históricos para la vida" se sabe representante del sentido histórico del siglo XIX y aunqué no cree en el "progreso" como el, según él, máximo representante del sentido histórico. Hegel, (en lo que sigue a su maestro Schopeuhauer, negador del progreso, particularmente en el orden moral) no tratará de proponernos sencillamente una vuelta a esta barbarie casi prehumana. El sabe como el hombre se ha hecho un animal interesante, hombre, no importa que el demasiado humano hombre, hombre al fin $y$ al cabo, merced al refinamiento y la introversión y al crecimiento de la geografía íntima que han sido consecuencia del predominio histórico de esta moral sacerdotal, grado superior de la de esclavos. Esto no aperece en la incomprensión de sus discípulos -incomprensión que él mismo profetizaba iba a disponer de él y a desfigurarlo antojadizamer. te o de críticos que como el escritor Papini repetirían esa apreciación tar fácil, tan superficial de Voltaire sobre Rousseau en célebre carta a éste: "volver a caminar en cuatro patas es lo que Ud. nos propone". No, ni es eso Nietzsche, ni eso fué Rousseau. Hombre originariamente bueno y pervertido por la sociedad, hombre malo y pervertido por la sociedad, no se trata de ropetirlel apera. Si, Qde quaella necesidad de siempre de

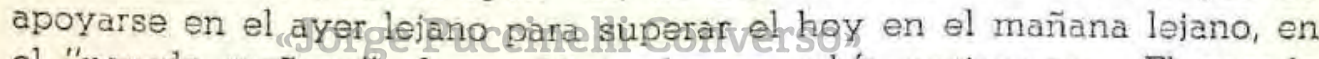
el "pasado mañana al que Nietzsche se sabía pertenecer. El pasado mañana que se habrá incorporado todos esos defectos del hoy como los de ayer y los habrá hecho trabajar en su provecho. El hombre distinquido, el grande hombre, el superhombre, objetivos de la tarea que según el filósofo poeta habrá de ocuparnos serán el progreso del que no cre en el progreso. Ellos justificarán y crearán el "gressus". Habrá habido camino y se habrá caminado hacia algo porque ellos serán - se harán- meta.

No es pues una simple reinstauración de la moral señorial lo que nos ofrecerá Federico Nietzsche Oehler sino una: ¡Trasmutación de todos los Valores!! (con verticales y vigorosos signos admirativos opuesta a esa otra que los tuvo curvilíneos y sinuosos, la de la moral de esclavos y sacerdotes) trasmutación de esa primera trasmutación, pues, pero cuyos hijos no habrán de ser los bárbaros antepasados.

(Continuará) 